\title{
Effect of Nanodisperse Carbon Fillers and Isocyanate Chain Extender on Structure and Properties of Poly(ethylene terephthalate)
}

\author{
Vladimir Agabekov, ${ }^{1}$ Vera Golubovich, ${ }^{2}$ and Stepan Pesetskiii ${ }^{2}$ \\ ${ }^{1}$ Institute of Chemistry of New Materials, National Academy of Sciences of Belarus, 36 F. Skoriny Street, 220141 Minsk, Belarus \\ ${ }^{2}$ V.A. Bely Metal-Polymer Research Institute, National Academy of Sciences of Belarus, 32a Kirov Street, 246050 Gomel, Belarus
}

Correspondence should be addressed to Vladimir Agabekov, agabekov@ichnm.basnet.by

Received 10 November 2011; Accepted 29 December 2011

Academic Editor: Sevan P. Davtyan

Copyright ( $) 2012$ Vladimir Agabekov et al. This is an open access article distributed under the Creative Commons Attribution License, which permits unrestricted use, distribution, and reproduction in any medium, provided the original work is properly cited.

\begin{abstract}
The effect of diisocyanate chain extender (CE) on the mechanical, rheological, and relaxation properties, as well as on molecular weight and crystallizability, of starting poly(ethylene terephthalate) (PET) and its composites containing carbon nanomaterials (CNM) such as carbon nanotubes (CNTs) and commercial carbon (CC) has been studied. The composites were compounded in molten PET using twin-screw extruder (screw diameter $35 \mathrm{~mm}$; L/D = 40). To improve the distribution of CNM in the polymeric matrix (before introduction into the melt), they were blended with PET powder and subjected to an ultrasonic treatment in methylene chloride. The salient features of the materials structure were estimated based on DSC and relaxation spectrometry (dynamic mechanical analysis) data. It has been found that CNM additives partly suppress the PET-chain extension reactions which take place during interaction between macromolecular end groups and CE. Besides, both CNT and CC favour crystallizability of the modified PET owing to nucleation of the crystallization process. The influence of CNT appears to be more effective than that of CC. Enhancements in true mechanical strength and deformability of PET/CE/CNM composites, as against $\mathrm{PET} / \mathrm{CE}$ materials, were found to be most clearly exhibited by the CNT-containing composites.
\end{abstract}

\section{Introduction}

poly(ethylene terephthalate) (PET) is one of the most important types among the thermoplastic polymers; its role in the human vital necessity is constantly growing. The major application areas for PET are fibers, films, beverage bottles, containers for food products, and so forth [1].

In recent years - a period of about last twenty yearsPET has been widely used more and more often in designing various composites for industrial purposes [2]. Composite materials that have no analogs in their economics and technical characteristics are developed on its base. Such materials include blends with polycarbonate $[3,4]$; olefin polymers and copolymers $[5,6]$; elastomers, poly(butylene terephthalate), styrene plastics $[7,8]$ and other polymers; materials reinforced by glass-fibers [2, 9]; fireproof composites [10] as well as systems containing small quantities of hard nanoparticles $[11,12]$.
An important problem arising during compounding and processing of PET composites-irrespective of their type-is hydrolytic as well as thermal degradation of polyester macromolecules. Breakdown reactions of PET macromolecules cause molecular weight reduction, deteriorate mechanical properties and impair technological characteristics [13].

The most important ways of slowing-down or preventing negative influence of macromolecular degradation on PET properties are incorporation of stabilizers, additional polycondensation of the material in the solid phase, using special chain extenders (CEs) [9]. The latter method is the most economically beneficial and efficient because it prevents macromolecules from both hydrolytic and thermal breakdown. CE mainly interacts with $-\mathrm{OH}$ or $-\mathrm{COOH}-$ end groups in polymer melt thus preventing molecular weight reduction. The reactions of interaction between CE and PET macromolecules easily take place in the melt in extrusion 
mixer-reactor when special catalysts and vacuum treatment are used.

Several researchers have reported $[4,9,14,15]$ that compounds containing isocyanate groups can be excellent CE for heterochain polyesters and their blends. However, together with the increase of PET molecular weight, partial crosslinking of macromolecules which slows down polymer crystallization is observed [15]. As a result, at first, the efficiency of molten PET processing drops because more time is required for crystallization of formed product that ensures its shape stability. Besides, mechanical properties and heat resistance of finished products can be impaired due to decreased crystallinity.

It is well known, on the other hand, that crystallization kinetics of thermoplastics, including PET, can be controlled by small quantities of nanofillers such as nanoclays and/or carbon nanomaterials (CNMs) $[15,16]$ added to compositions. It is of interest, therefore, to understand the joint influence of CE and CNM on structural transformations in PET, the set of technological relaxation, and physicomechanical characteristics of the obtained materials. The present work considers the stated problem using as an example PET composites containing diisocyanate $\mathrm{CE}$ along with carbon nanotubes and commercial carbon (CC).

\section{Experimental}

2.1. Materials. The experiments were conducted using granulated PET of commercial grade supplied by Mogilevkhimvolokno Co. (PET-8200 intended for making beverage bottles, containers or any other packaging items); having intrinsic viscosity in dichloroacetic acid, $0.700 \mathrm{dL} / \mathrm{g}$; concentration of end carboxyl groups, $24 \mathrm{mmol} / \mathrm{kg}$; glass-transition temperature, $T_{g}=76.5^{\circ} \mathrm{C}$. A powdery PET prepared by size reduction of PET-8200 granules in liquid nitrogen was also used. The powder particle size did not exceed $300 \mu \mathrm{m}$.

Multilayer CNTs produced at Heat-and-Mass Exchange Research Institute, NAS of Belarus, were used as carbon nanofillers. The technology of obtaining CNT is based on reaction of $\mathrm{H}_{2}, \mathrm{CO}$, and $\mathrm{N}_{2}$ in the plasma of highvoltage discharge at atmospheric pressure. The CNT were purified from amorphous carbon, diamond, and fullerene fractions by sedimentation and extraction in benzene. CNT dimensions were diameter, 5-30 nm, length, $0.5-3.0 \mu \mathrm{m}$ (Figure 1). At initial state, CNTs were chaotically intertwined structural units of different lengths and diameters (Figure 1). Besides CNT, technical carbon No. 220 (Specifications 38 41558-97, supplied by Tekhuglerod Co., Omsk) was tested: average particle size, $13-85 \mathrm{~nm}, \mathrm{pH}=6-8$ of aqueous suspension; specific external surface area, $111 \mathrm{~m}^{2} / \mathrm{kg}$; iodine number, $121 \mathrm{~g} / \mathrm{kg}$; dibutylphthalate sorption, $100 \mathrm{~cm}^{3} / 100 \mathrm{~g}$.

The modifier APEC-MM (Specifications by 400084698 .151-2004) containing diisocyanate and stabilizer (ST) against thermal degradation of PET macromolecules was used as a CE. The compositions of test materials are listed in Table 1.

2.2. Compounding and Specimens Preparation. Test materials were compounded as follows. The CE powdery PET and

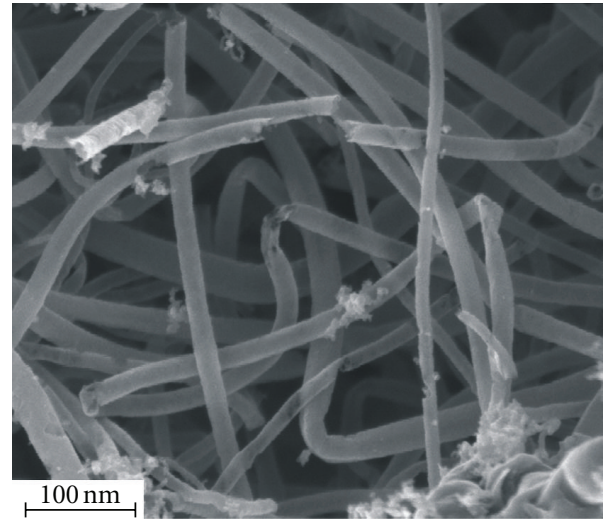

FIGURE 1: Electron photomicrograph of CNT.

TABle 1: Compositions of test materials.

\begin{tabular}{lcccccc}
\hline \multirow{2}{*}{ Number } & \multicolumn{7}{c}{ Components (wt.\%) } \\
& PET & Powdery PET & NT & CC & CE & ST \\
\hline I & 99.00 & 0.8 & & & & 0.2 \\
II & 98.00 & 0.9 & & & 0.9 & 0.2 \\
III & 97.99 & 0.9 & 0.01 & & 0.9 & 0.2 \\
IV & 97.95 & 0.9 & 0.05 & & 0.9 & 0.2 \\
V & 97.99 & 0.9 & & 0.01 & 0.9 & 0.2 \\
VI & 97.95 & 0.9 & & 0.05 & 0.9 & 0.2 \\
\hline
\end{tabular}

CNM were together subjected to ultrasonic treatment (sonication) in methylene chloride at the following conditions: instrument UZDN-1U32 (Russia), frequency, $22 \mathrm{kHz}$; duration, $15 \mathrm{~min}$; initial temperature, $23^{\circ} \mathrm{C}$. Then, the methylene chloride was "vacuum-evaporated" at $\approx 30^{\circ} \mathrm{C}$. The powder prepared was added to PET granulate previously dried up to residual humidity below $0.02 \%$; the mix was thoroughly stirred in a high-speed two-blade mixer. After that, the components were reactively mixed in molten PET. The work was done on an extrusion-granulating line based on the twin-screw extruder TSSK-35/40 (China): the screw diameter $35 \mathrm{~mm}$; $\mathrm{L} / \mathrm{D}=40 ; 10$ separate zones of heating the material cylinder; vacuuming zone and the screws of special configuration to provide for a high dispersion degree of the components as well as their uniform distribution throughout PET bulk. The melt temperature in the reactive mixing zone was $270^{\circ} \mathrm{C}$. From the material cylinder of the extruder the material appeared as strands; they were water cooled and granulated on a rotor-type granulating device. The granulate produced was used to make test samples and do physicochemical analysis.

The test samples for testing mechanical properties of the materials were injection moulded on a machine EN-30 (Taiwan); screw diameter $35 \mathrm{~mm}$; injection volume $30 \mathrm{~cm}^{3}$. The injection mould's temperature was maintained at $45 \pm$ $5^{\circ} \mathrm{C}$.

2.3. Characterization. The relaxation spectrometry technique was employed using test specimens in the form of 
TABLE 2: Property values for polyester materials.

\begin{tabular}{|c|c|c|c|c|c|c|c|c|c|}
\hline \multirow{2}{*}{ Composition } & \multirow{2}{*}[\eta]{$(\mathrm{dL} / \mathrm{g})$} & \multirow{2}{*}{$\mathrm{M}_{n}$} & \multirow{2}{*}{ MFI (g/10 min) } & \multirow{2}{*}{$\sigma_{\mathrm{uf}}^{\mathrm{b}}(\mathrm{MPa})$} & \multirow{2}{*}{$\sigma_{\mathrm{tt}}^{\mathrm{c}}(\mathrm{MPa})$} & \multirow{2}{*}{$\sigma_{r}(\mathrm{MPa})$} & \multirow{2}{*}{$\varepsilon_{r}(\%)$} & \multicolumn{2}{|c|}{ S (\%) } \\
\hline & & & & & & & & $\mathrm{S}_{\text {II }}$ & $\mathrm{S}_{\perp}$ \\
\hline $\mathrm{I}^{\mathrm{a}}$ & 0.634 & 16006 & 23.0 & 54 & 199 & 42 & 374 & 0.85 & 0.54 \\
\hline II & 0.746 & 22626 & 16.7 & 54 & 256 & 50 & 412 & 0.75 & 0.53 \\
\hline III & 0.728 & 21480 & 18.8 & 55 & 282 & 55 & 412 & 1.23 & 0.58 \\
\hline IV & 0.727 & 21417 & 19.5 & 56 & 325 & 60 & 441 & 1.21 & 0.66 \\
\hline $\mathrm{V}$ & 0.723 & 21411 & 18.9 & 53 & 270 & 53 & 410 & 0.95 & 0.56 \\
\hline VI & 0.737 & 22049 & 18.0 & 56 & 300 & 58 & 418 & 0.96 & 0.54 \\
\hline
\end{tabular}

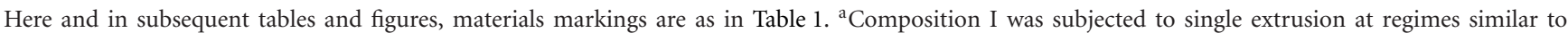
compounding of Compositions II-VI. ${ }^{\mathrm{b}} \sigma_{\mathrm{uf}}$ is upper flow limit. ${ }^{\mathrm{c}} \sigma_{\mathrm{tt}}=\sigma_{r}\left(1+\varepsilon_{r} / 100\right)$ is true tensile strength, where $\sigma_{r}$ and $\varepsilon_{r}$ are, respectively, strength and relative elongation at break.

plates, $50 \times 5 \times 1 \mathrm{~mm}$. They were made on a piston moulding machine of laboratory version, the injection volume being $2.5 \mathrm{~cm}^{3}$.

The values of mechanical properties of the materials in tension were determined using a multipurpose machine Instron 5657 (UK). Experimental samples were of Type 5 $(50 \times 5 \times 3 \mathrm{~mm})$. In compliance with Russian GOST 1162 related to the determination of arithmetical mean parameter of mechanical properties, at least five samples were used. The samples, for which deviations from the arithmetical mean values did not exceed $10 \%$, were used in calculations. The shrinkage was determined according to GOST 18616 on bars with size $80 \times 10 \times 4 \mathrm{~mm}$; were moulded by injecting melt at one butt end of the mould. The measurements were done longitudinally $\left(\mathrm{S}_{\mathrm{II}}\right)$ and perpendicularly $\left(\mathrm{S}_{\perp}\right)$ to the melt flow direction.

Variations in molecular weight of PET were estimated by viscosity measurements conducted at $25^{\circ} \mathrm{C}$ with a capillary viscometer Ubbelohde; dilute solutions ( 0.5 parts of PET in $50 \mathrm{~mL}$ of solvent); the solvent was dichloroacetic acid of "chemically pure" grade. Every solution was agitated for $60 \mathrm{~min}$ at $60^{\circ} \mathrm{C}$ until PET became completely dissolved. The dependence between intrinsic viscosity $([\eta])$ and numbermean molecular weight $\left(\mathrm{M}_{n}\right)$ of PET was found from MarkHouwink's equation [17]:

$$
[\eta]=0.0067 \cdot \mathrm{M}_{n}^{0.47} .
$$

Rheological properties of the materials were judged by the melt flow index (MFI) determined on the instrument IIRT-AM (Ukraine) at $T=265^{\circ} \mathrm{C}$, load $P=21.6 \mathrm{~N}$, and capillary diameter, $\varnothing=2.095 \mathrm{~mm}$.

The material structure was studied by differential scanning calorimetry (DSC) technique using microcalorimeter DSM-10 M (Institute for Biological Instrumentations, RAS, Russia); sample weight, $10 \mathrm{mg}$; scanning rate, $16^{\circ} \mathrm{C} / \mathrm{min}$.

The dynamic mechanical (relaxation) properties of the materials were found by analyzing temperature dependences of the mechanical loss tangent $(\tan \delta)$ and dynamic shear modulus $\left(G^{\prime}\right)$ of the samples. The tests were performed using a reverse torsion pendulum (designed at MPRI NAS of Belarus) $[3,15]$; the frequency was $1 \mathrm{~Hz}$. The temperature measurement accuracy was $0.1{ }^{\circ} \mathrm{C}, \tan \delta, \pm 3 \% ; \mathrm{G}^{\prime}, \pm 1 \%$.

\section{Results and Discussion}

3.1. Rheological and Mechanical Properties. It is clear from Table 2 that modification of PET by addition of CE and CNM substantially influences the parameters that characterize molecular structure, along with values of mechanical and technological properties of the materials. There is a noticeable difference in the effects of $\mathrm{CE}$ alone and its combination with CNM. Thus, the addition of CE leads to the increase of intrinsic viscosity and noticeable reduction of MFI values, which results from increased molecular weight of PET [4, 15]. $\mathrm{M}_{n}$ 's growth (MFI reduction) of PET containing CNM is not very substantial. This can be explained by high adsorptive (chemisorptive) surface activity of CNT and CC that causes partly blocking CE s isocyanate groups, and consequently, the decrease of the output of products of its interaction with ending groups of PET macromolecules [12, 14].

It is worth mentioning that PET containing both $\mathrm{CE}$ and CNM shows a higher tensile deformability than the material containing only CE (Table 2, Figure 2). This effect is most pronounced in composites containing CNT (Table 2). With $0.05 \mathrm{wt} . \%$ of CNM (CNT or CC), the deformation curve changes because the material becomes stronger owing to orientational stretching of the sample neck. The calculated true strength values of the material (Table 2) show maximum tensile strength $\sigma_{\mathrm{tt}}$ for Composition IV, containing CE and CNT -0.05 wt. \% exceeds $300 \mathrm{MPa}$. It appears that PET containing $\mathrm{CE}$ and CNT tends to have orientational stretching and its strength considerably increases. This fact shows a possibility of obtaining stronger PET fiber by modifying polyester with CE and CNT. The reinforcing effect of CE and CNM added simultaneously can be explained as follows.

The reinforcing effect of CE and CNM added simultaneously can be explained as follows. The chemisorptive interaction of one of the CE s diisocyanate groups with CNM surface functionalizes the nanofiller surface. More possibilities arise for strengthening the bond between the nanofiller particles and PET macromolecules. This may happen through interaction of free isocyanate groups in $\mathrm{CE}$ chemisorbed on CNM nanoparticles with terminal hydroxyl or carboxyl groups of PET macromolecules, Polar van der waals interactions with intramolecular ester groups, and so forth. It is quite possible that inter chain bonding of PET 


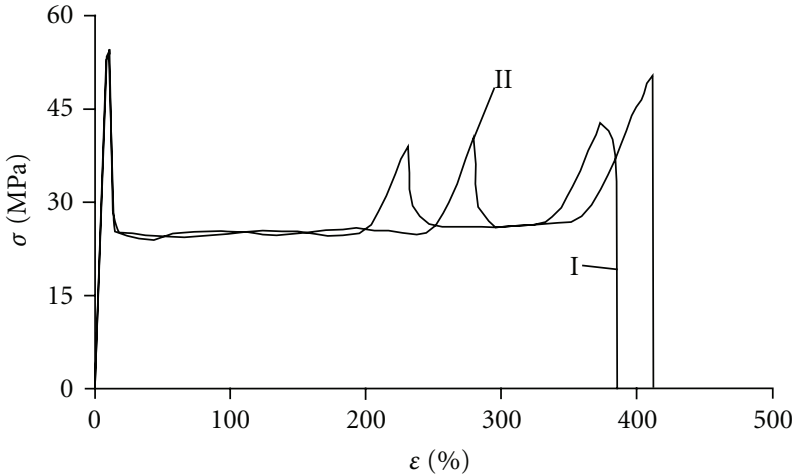

(a)

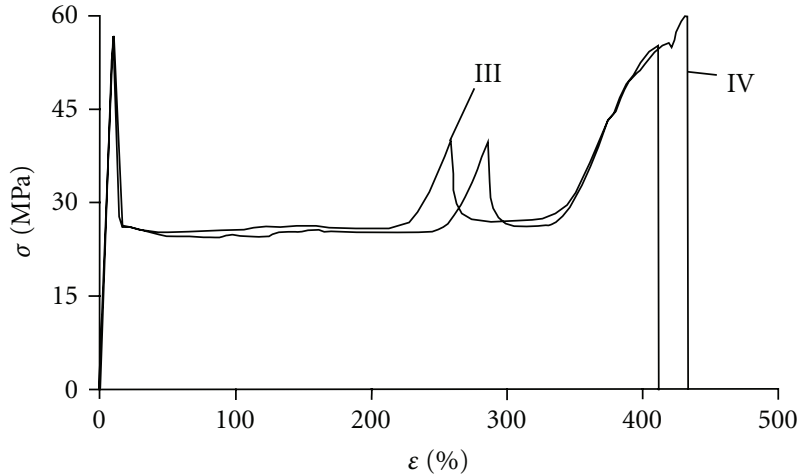

(b)

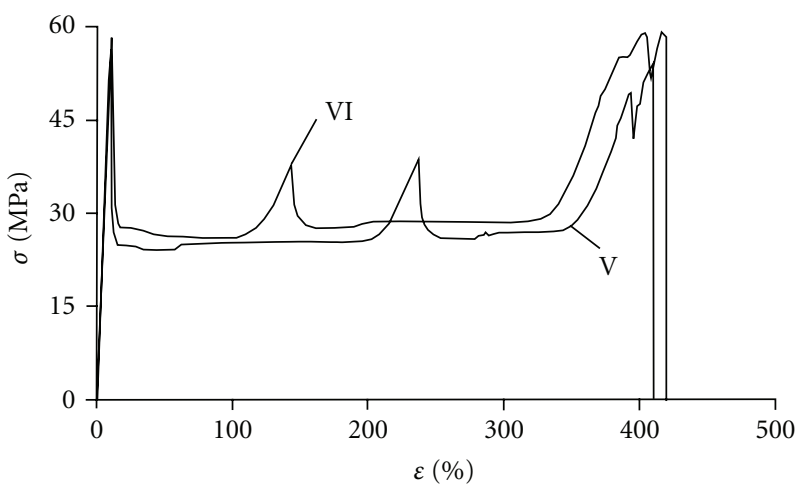

(c)

FIGURE 2: Deformation plots for materials.

macromolecules by means of the functionalized filler can happen in the presence of two free isocyanate groups in CE that was chemisorbed on CNM surface. It is obvious from the data in Table 2 and Figure 2 that the influence of CNT is stronger than that of CC.

Schemes of probable reactions for PET/CE, CNM/CE and PET/CNM/CE are shown in Figure 3.

3.2. DSC Observations. It is clear from Table 2 that pure CE added to PET causes shrinkage to reduce, whereas CNM increases the latter; the shrinkage increases more noticeably in case of CNT. This event is explained by specific influence of modifying additives on PET crystallization.

Indeed, it can be seen from Table 3 and Figure 4 that $\mathrm{CE}$ rises the temperature of cold crystallization $\left(T_{c \text { cr }}\right)$ and decreases the temperature of crystallization from the melt $\left(T_{\mathrm{cr}}\right)$ which results from the delay of crystallization processes owing to higher molecular weight of PET [4]. The addition of CNM together with CE leads to a noticeable enhancement in PET crystallizability. Crystallization proceeds faster when CNT is used: addition of nanotubes accelerates both cold crystallization and that from the melt in comparison with polyester non-modified with CE (Table 3 ). The use of CC in PET reduces the cold crystallization temperature (by 2.6$4.6^{\circ} \mathrm{C}$ ) of the material as against the starting PET. However, irrespective of filler concentration, however, the $T_{\mathrm{cr}}$-values
TABLE 3: DSC values for polyester materials.

\begin{tabular}{lccccc}
\hline Composition & $\begin{array}{c}T_{c \mathrm{cr}} \\
\left({ }^{\circ} \mathrm{C}\right)\end{array}$ & $\begin{array}{c}\Delta H_{c \mathrm{cr}} \\
(\mathrm{J} / \mathrm{g})\end{array}$ & $\begin{array}{c}T_{m}{ }^{\mathrm{a}} \\
\left({ }^{\circ} \mathrm{C}\right)\end{array}$ & $\begin{array}{c}T_{\mathrm{cr}}{ }^{\mathrm{a}} \\
\left({ }^{\circ} \mathrm{C}\right)\end{array}$ & $\begin{array}{c}\Delta H_{\mathrm{cr}}{ }^{a} \\
(\mathrm{~J} / \mathrm{g})\end{array}$ \\
\hline I & 130.4 & 28.2 & 253.3 & 194.4 & 27.7 \\
II & 132.3 & 17.2 & 248.4 & 187.7 & 22.3 \\
III & 126.1 & 12.5 & 245.0 & 197.0 & 35.4 \\
IV & 128.3 & 13.0 & 246.8 & 197.6 & 37.2 \\
V & 127.6 & 9.8 & 248.9 & 188.2 & 35.8 \\
VI & 125.8 & 12.1 & 244.0 & 192.9 & 39.8 \\
\hline
\end{tabular}

${ }^{\mathrm{a}}$ The values were obtained after repeated heating (cooling) of samples.

(from the melt) remain somewhat lower in comparison with the initial polymer. It can be concluded that CNT are more advantageous as crystallization nucleator than CC for PET composites containing CE.

Some growth of crystallinity is observed under the influence of $\mathrm{CNM}$ what follows from the comparison of latent heat values of crystallization $\left(\Delta H_{\mathrm{cr}}\right)$ of the materials (Table 3). Somewhat lower crystallinity of the materials containing CNT as against those with CC (Table 2) can be explained by the fact that nanotubes generate excessively great number of crystallization nuclei that prevent crystals from growing because of geometric (spatial) limits. Retarded 


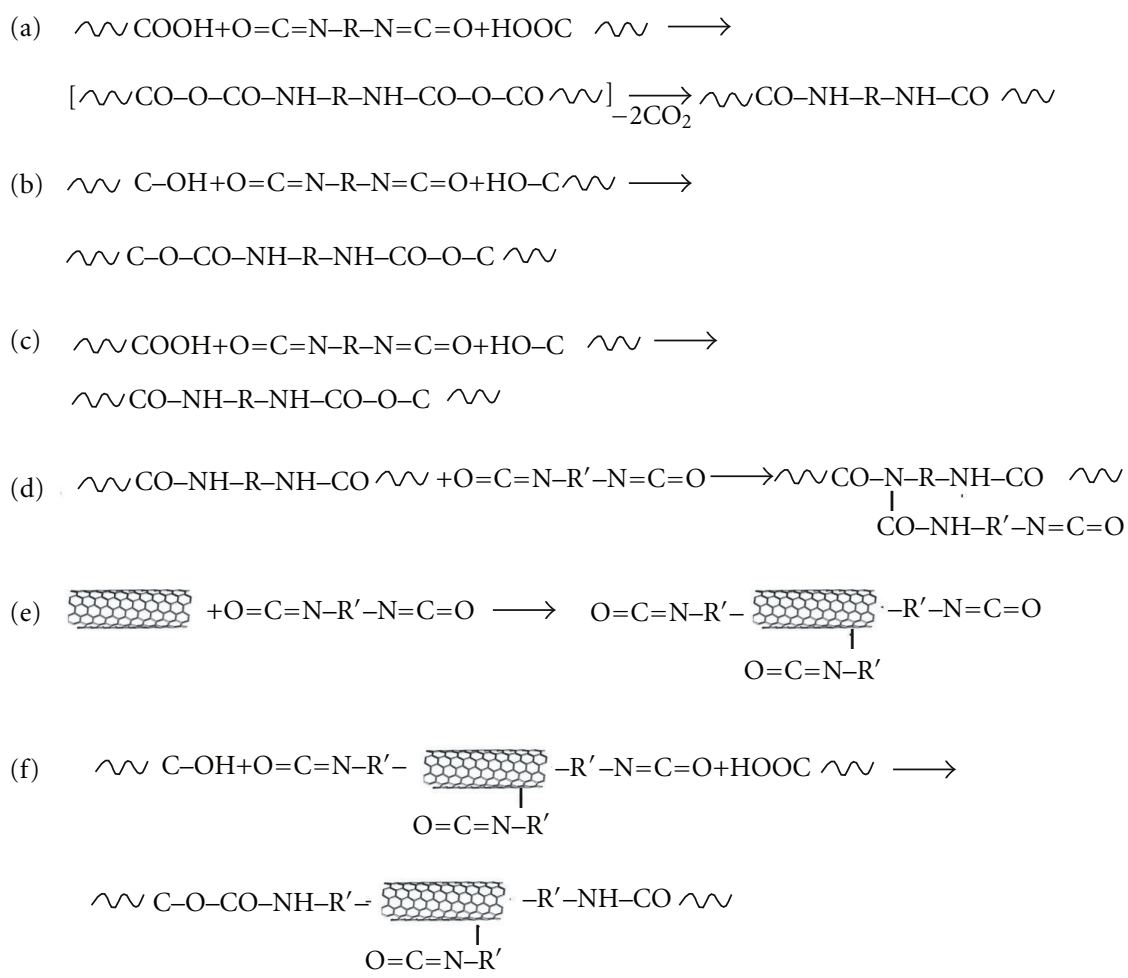

FIGURE 3: Schematics of probable reactions taking place with diisocyanate CE participation. (a) Chain extension caused by interaction of CE with terminal carboxyl (groups). (b) Chain extension caused by interaction of CE with terminal hydroxyl. (c) Chain extension caused by interaction of CE and PET macromolecules. (e) CNT functionalization. (f) Chain extension at the expense of functionalized CNT.

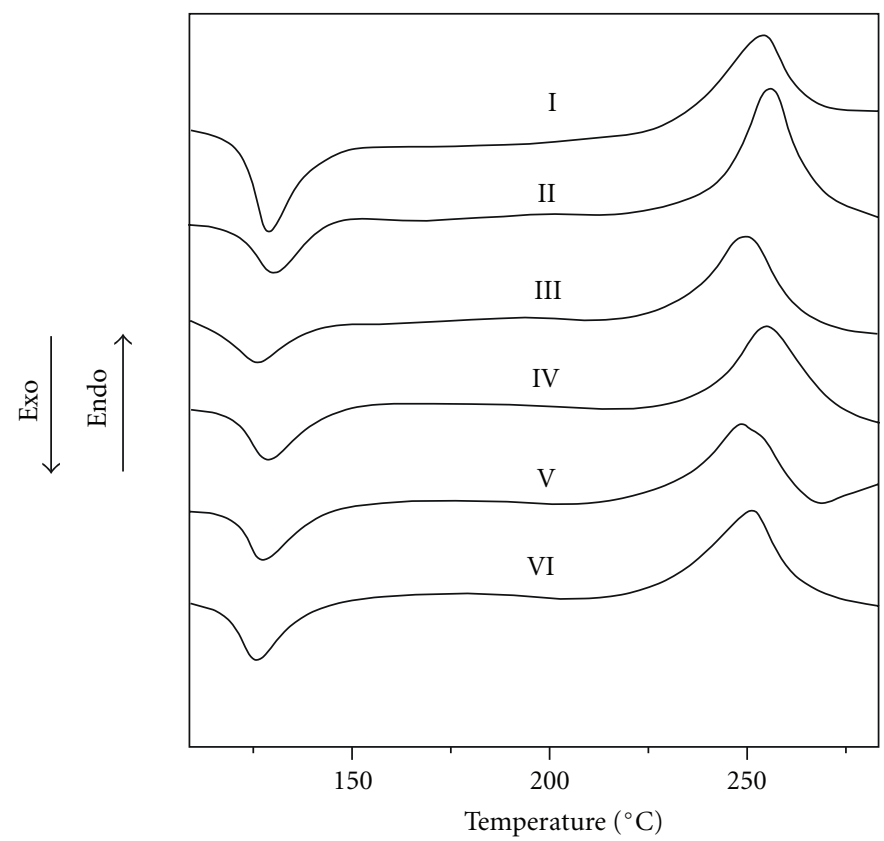

(a)

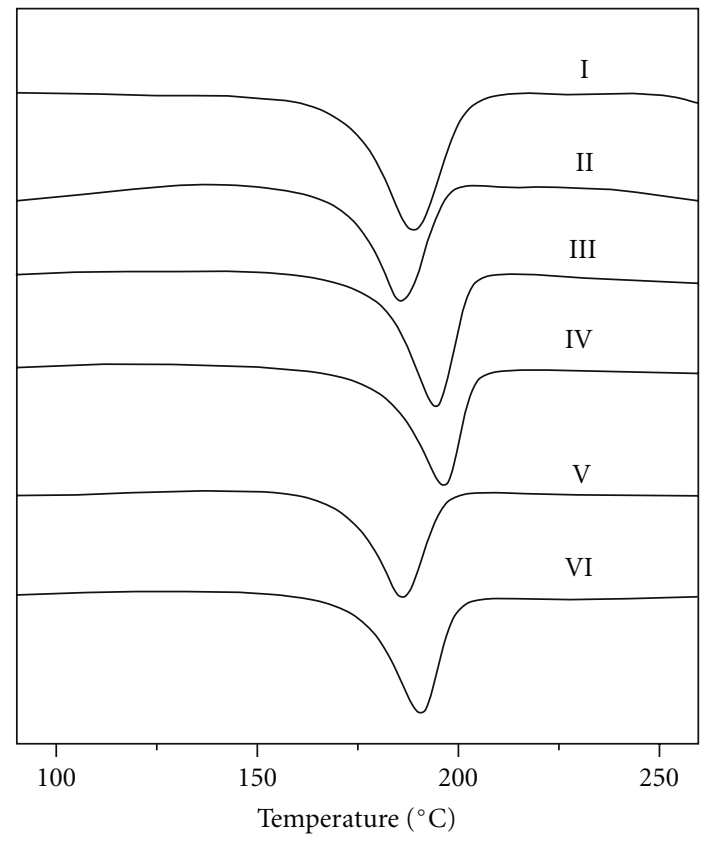

(b)

FIGURE 4: DSC curves of materials: (a) heating, (b) cooling of samples. 

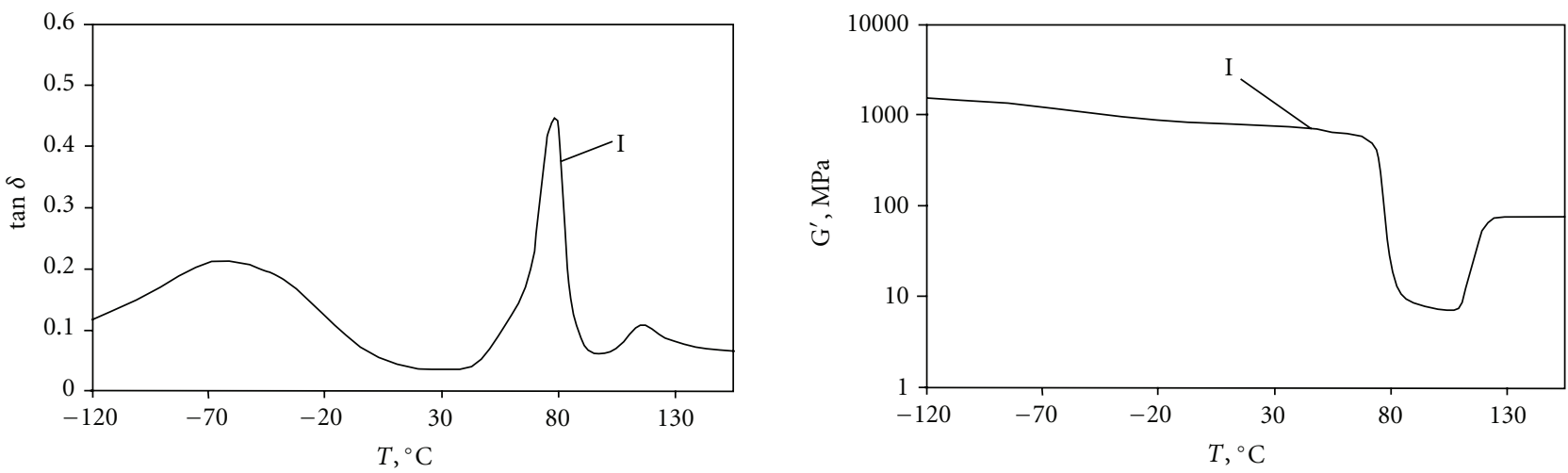

(a)
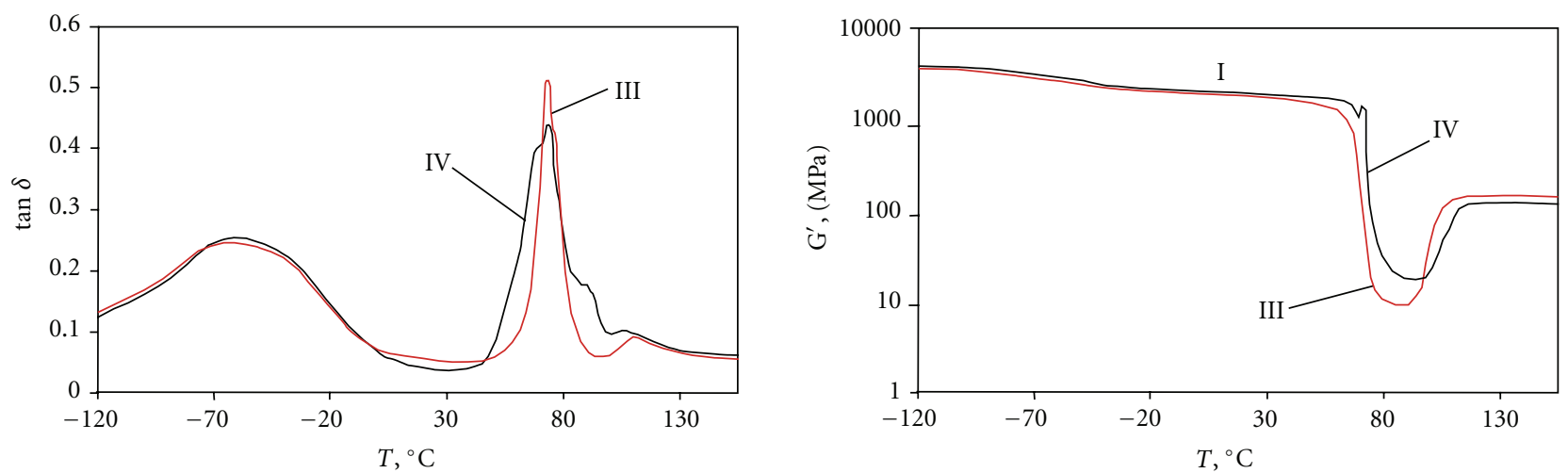

(b)
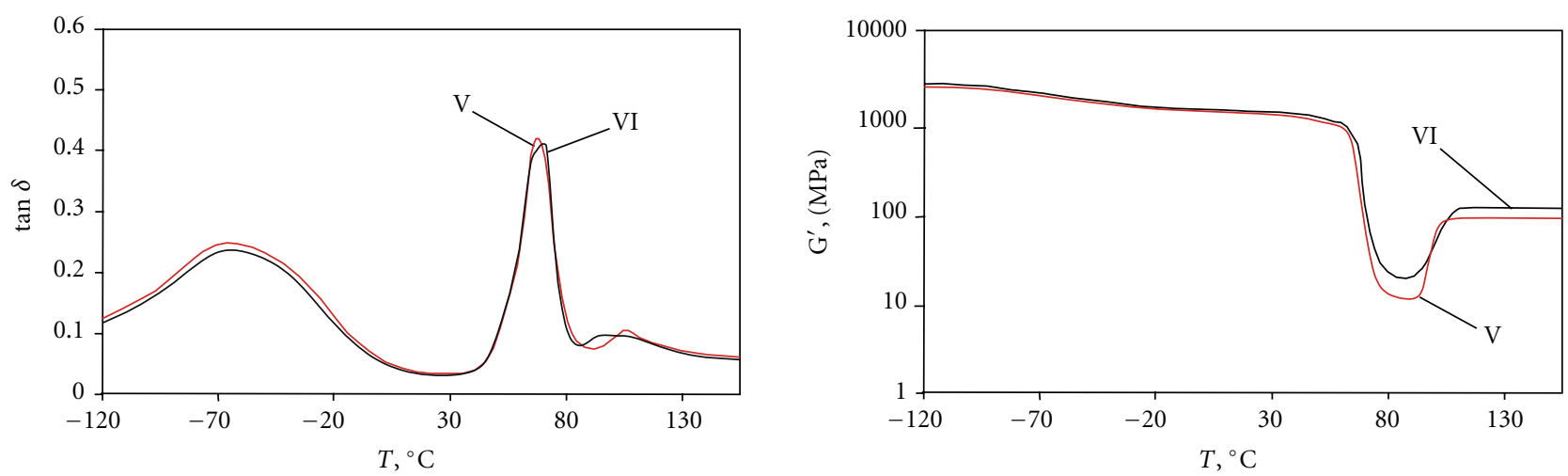

(c)

Figure 5: Temperature dependence of mechanical loss tangent $(\tan \delta)$ and dynamic shear modulus $\left(\mathrm{G}^{\prime}\right)$ of materials (numbers correspond to compositions in Table 1). (a) I; (b) III-IV; (c) V-VI.

growth of crystals in spite of their accelerated nucleation has been reported elsewhere [18] where polyamide 6 crystallization had been investigated in the presence of nanodispersed clay minerals.

Therefore, simultaneous addition of CE and CNM to PET can result in composites with an increased molecular weight and enhanced crystallizability as against the starting polyester. CNM (especially CNT) levels the inhibiting effect of CE upon PET crystallization.
3.3. Relaxation Spectrometry. It has already been mentioned that adsorptive (chemisorptive) interaction between polymer macromolecules and filler particles surface can explain the influence of CNM on the structure and physicomechanical properties of PET composites. The relaxation spectrometry data (Table 4, Figure 5) can prove this statement. The presence of CE and CNM in PET does not change $T_{g}$ values determined by the temperature location of the glass-transition peak maximum point in the temperature dependence of 
TABLE 4: Values of parameters characterizing relaxation properties of polyester materials.

\begin{tabular}{lccc}
\hline Composition & $T_{g}\left({ }^{\circ} \mathrm{C}\right)$ & $T_{\beta}\left({ }^{\circ} \mathrm{C}\right)$ & $\mathrm{G}_{\min }^{\prime}{ }^{\mathrm{a}}(\mathrm{MPa})$ \\
\hline I & 76.5 & -61.3 & 8 \\
II & 75.5 & -64 & 3 \\
III & 75.6 & -60.1 & 11 \\
IV & 76.5 & -58.2 & 15 \\
& (excess at 93.3) & & \\
V & 75.7 & -60.7 & 10 \\
VI & 75.9 & -60.1 & 13 \\
& (excess at 90.3) & & \\
\hline
\end{tabular}

${ }^{a} \mathrm{G}_{\text {min }}^{\prime}$ is dynamic shear modulus at $90-95^{\circ} \mathrm{C}$.

mechanical loss tangent. However, at concentration of CNM $=0.05 \mathrm{wt} . \%$, excesses (Figure 5 ) in the high temperature portions of the glass-transition peak are observed. Most likely the presence of excesses is due to mobility devitrification of macromolecular segments connected through adsorption with CNM particles surface. Under the effect of CNM, $T_{\beta}$ values increase owing to mobility devitrification within an elemental unit of PET macromolecules; the growth of minimal values of dynamic shear modulus $\mathrm{G}^{\prime}$ min within the zone of high elasticity (at $T \approx 90-95^{\circ} \mathrm{C}$ ) occurs which can also be explained by active adsorptive interaction between macromolecular fragments and CE-modified CNM surface.

These findings are indicative of prospects for designing and testing polyester composites containing CE and CNM. Investigations in this direction are undoubtedly of scientific interest and are of great importance for scientific substantiation of technology for making competitive and advantageous composites intended for industrial applications; also fibertype materials of new generation.

\section{Conclusions}

Comparative analysis of molecular structure, relaxation, and mechanical properties of PET and its composites containing carbon fillers like nanotubes or commercial carbon and also diisocyanate $\mathrm{CE}$ has been conducted. It has been showed that reactions leading to chain extension proceed easily in the presence of carbon nanofillers. At the same time, retardation of crystallization of PET occurring under the influence of $\mathrm{CE}$ is leveled in the presence of carbon nanofillers; this effect is most pronounced in composites containing CNT. PET modified in the melt by CNT and CE appears to be perspective for making block-type articles and reinforced fibers.

\section{Acknowledgment}

The authors wish to thank A. V. Krauklis for supplying CNT and their electron photomicrographs.

\section{References}

[1] D. Brooks and D. Jyle, Manufacture of PET Packaging Products, Profession, Saint Petersburg, Russia, 2006.
[2] S. S. Pesetskii, B. Yurkowsky, and V. E. Agabekov, "Poly(alkyleneterephthalate)-based composite materials: state of art and future developments," in Proceedings of the International Conference on Polymer Composites and Tribology (Polycomtrib '11), pp. 7-9, Gomel, Belarus, 2011.

[3] S. S. Pesetskii, B. Jurkowski, and V. N. Koval, "Polycarbonate/ polyalkylene terephthalate blends: interphase interactions and impact strength," Journal of Applied Polymer Science, vol. 84, no. 6, pp. 1277-1285, 2002.

[4] X. Tang, W. Guo, G. Yin, B. Li, and C. Wu, "Reactive extrusion of recycled poly(ethylene terephthalate) with polycarbonate by addition of chain extender," Journal of Applied Polymer Science, vol. 104, no. 4, pp. 2602-2607, 2007.

[5] J. G. Park, D. H. Kim, and K. D. Suh, "Blends of polyethyleneterephthalate with EPDM through reactive mixing," Journal of Applied Polymer Science, vol. 78, no. 12, pp. 2227-2233, 2000.

[6] K. Friedrich, M. Evstatiev, S. Fakirov, O. Evstatiev, M. Ishii, and M. Harrass, "Microfibrillar reinforced composites from PET/PP blends: processing, morphology and mechanical properties," Composites Science and Technology, vol. 65, no. 1, pp. 107-116, 2005.

[7] N. Papke and J. Karger-Kocsis, "Thermoplastic elastomers based on compatibilized poly(ethylene terephthalate) blends: effect of rubber type and dynamic curing," Polymer, vol. 42, no. 3, pp. 1109-1120, 2001.

[8] K. H. Yoon, H. W. Lee, and O. O. Park, "Reaction effect on the properties of poly (ethylene terephthalate) and poly(styreneco-maleic anhydride) blends," Polymer, vol. 41, no. 12, pp. 4445-4449, 2000.

[9] J. Scheirs and T. E. Long, Modern Polyesters: Chemistry and Technology of Polyesters and Copolyesters, Wiley, Chichester, UK, 2003.

[10] S. V. Levchik and E. D. Weil, "Flame retardancy of thermoplastic polyester - A review of the recent literature," Polymer International, vol. 54, no. 1, pp. 11-35, 2005.

[11] S. Pavlidou and C. D. Papaspyrides, "A review on polymerlayered silicate nanocomposites," Progress in Polymer Science, vol. 33, no. 12, pp. 1119-1198, 2008.

[12] M. Moniruzzaman and K. I. Winey, "Polymer nanocomposites containing carbon nanotubes," Macromolecules, vol. 39, no. 16, pp. 5194-5205, 2006.

[13] S. G. Kudyan, O. V. Filimonov, and S. S. Pesetskii, "Molecularstructural transformations in poly(ethyleneterephthalate) processed from the melt," Materials. Technologies. Instrument, vol. 12, no. 3, pp. 27-32, 2007.

[14] S. S. Pesetski, O. V. Filimonov, V. N. Koval, and V. V. Golubovich, "Structural features and relaxation properties of $\mathrm{PET} / \mathrm{PC}$ blends containing impact strength modifier and chain extender," Express Polymer Letters, vol. 3, no. 10, pp. 606-614, 2009.

[15] S. S. Pesetskii, B. Jurkowski, O. V. Filimonov, V. N. Koval, and V. V. Golubovich, "PET/PC blends: effect of chain extender and impact strength modifier on their structure and properties," Journal of Applied Polymer Science, vol. 119, no. 1, pp. 225-234, 2011.

[16] S. Goeringer, N. R. De Tacconi, C. R. Chenthamarakshan, K. Rajeshwar, and W. A. Wampler, "Redox characterization of furnace carbon black surfaces," Carbon, vol. 39, no. 4, pp. 515$522,2001$.

[17] W. R. Moore and D. Sanderson, "Viscosities of dilute solutions of polyethylene terephthalate," Polymer, vol. 9, pp. 153-158, 1968.

[18] T. D. Fornes and D. R. Paul, "Crystallization behavior of nylon 6 nanocomposites," Polymer, vol. 44, no. 14, pp. 3945-3961, 2003. 

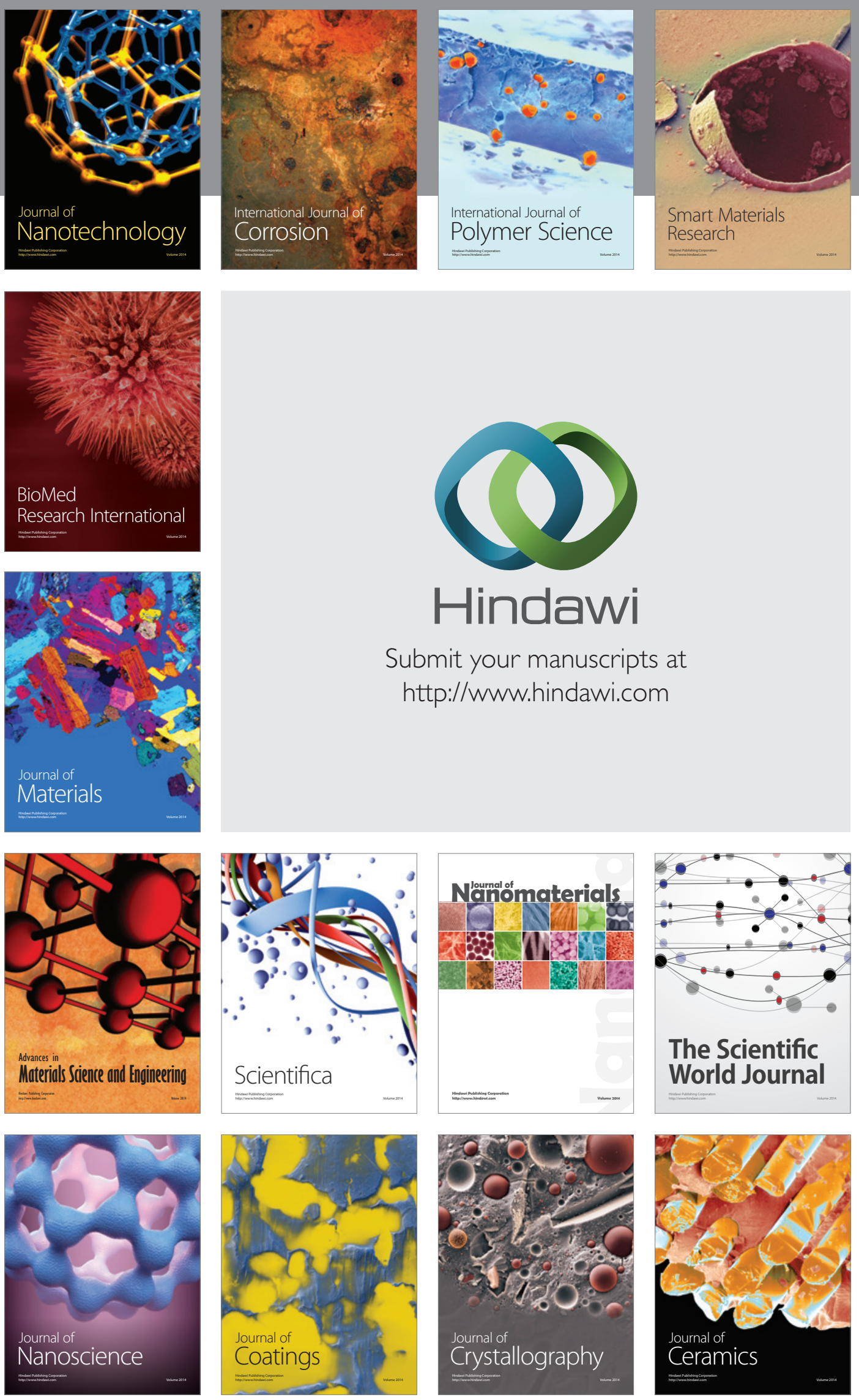

The Scientific World Journal

Submit your manuscripts at

http://www.hindawi.com

\section{World Journal}

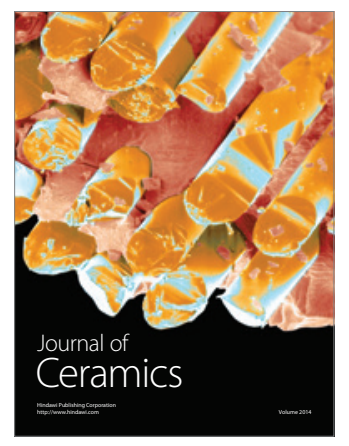

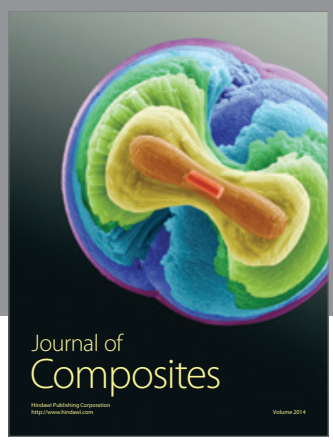
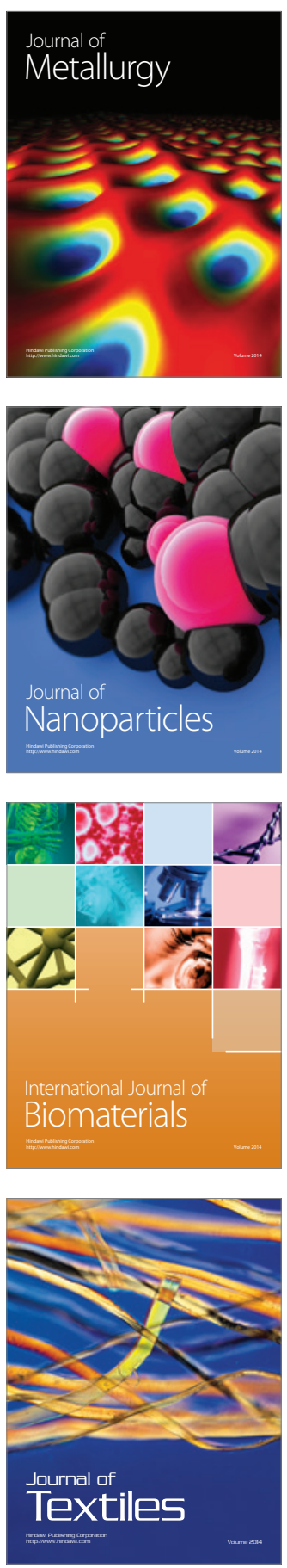